\title{
Dry season survey of aspergilli in the air of Benin City, Nigeria
}

\author{
J. A. OKHUOYA, E. N. OSOLU
}

Department of Betany. University of Benin, PMB 1154. Benin City. Nigeria

\begin{abstract}
Ok hu oy 3 I. A, O s o Iu E. N.: Dry season survey of aspergilli in the air of Benin City. Nigeria. Acta Mycol. XXVI (2): 83.88 .1990 .

In both indoor survey of the air over Benin. eleven species of Aspergillus were commonly found. Thete were more species in the air in January than in February and March. The spore concentration of these species in the air was found to be associated with the environmental condition, vegetation and human activities of each area of the city sampled. Most of them showed a consistent diumal pattern while others were inconsistent. However $A$. verricolor and $A$. tamarii exhibited double peak patierns. Arnong the substrates used in trapping these fungi. yam recorded the highest number of Aspergillus species (11).
\end{abstract}

INTRODUCTTON

The earth's atmosphere contains a vast complex of airborne spores and pollen, (air spores) the composition and concentration of which are subject continuous diurnal and seasonal variations (H a r v e y, M u $11 \mathrm{i}$ n s, 1975; Gre g o r y, 1978). Air spores have been studied more extensively in temperature countries (H a r v e y, 1970; P a d y, 1957; G r e g or y, 1978) than in the tropics (A y a n r u, 1981; C a m m a c k, 1955; D r a n f i e 1 d, 1966; Og un 1 a n a, 1975; Meredith, 1962).

Climatic factors, particularly temperature, rainfall and relative humidity, have a direct effect on the manner in which spores are released into the atmosphere (H o d g k i s s, H a r v e y, 1970). Also the vegetation of the neighbourhood on which saprophytic and parasitic fungi develop, affect the air spores of any given locality. General information derived from air spore studies are useful in disease forecasting and control. 
The genus Aspergillus which displays the widest spectrum of species, is a major component of the air spores. Many species in this genus are deteriogenes of agricultural and industrial products and most cause human diseases like aspergillosis. They also constitute a major group of laboratory contaminants, and grow easily on many substrates.

Airborne fungal spores are difficult to study because their sources of origin are often microscopic and difficult to detect ( $\mathrm{H}$ a r v e y, 1973). Hence in most fungal air surveys, airborne conidia of Aspergillus are considered at the generic level. They are thus either grouped as an unclassified category or expressed as hyaline unidentified spores together with penicillia and some members of the deuteromycetes ( $\mathrm{H}$ u d s o n, 1969). In such surveys, Aspergillis has been found to form a relatively low proportion of the air spores, especially in the temperate latitudes. However $\mathrm{S}$ h a f u e and $\mathrm{R}$ a h $\mathrm{m}$ a $\mathrm{n} \mathrm{i} \mathrm{(1978)} \mathrm{in} \mathrm{Iran} \mathrm{found} \mathrm{Aspergillus}$ to be one of the most abundant moulds they trapped. Also in the tropics, Sreeramulu and Seshast a r a m (1962) found that Aspergillus was the fourth commonest group in the fungal spores in India.

Specific air surveys for Aspergillus are very limited, both in the temperature and tropic countries. The only specific study on this genus is the one by $\mathrm{H} \mathrm{u} \mathrm{d} \mathrm{s} \mathrm{o} \mathrm{n}$ (1969). In a year study (1966-1967) using an Anderson sampler he identified 14 species without reference to their diurnal pattern of occurrence in the air. There has been no such study in tropical climates like Nigeria. This study was therefore undertakened to identify the different species of Aspergillus in the air over Benin City, and to determine their diurnal patterns of occurrence in the air.

\section{MATERIALS AND METHODS}

Air was sampled in seven sites in Benin City namely, Iyaro, Ugbowo campus of the University of Benin, the markets in Uselu, New Benin, Ring Road, the Central Hospital, and University of Benin Teaching Hospital (U.B.T.H.). The settle plate method was used in the sampling.

Three ( $9 \mathrm{~cm}$ diameter) Petri dishes containing acidified potato aextrose agar (PDA) were exposed for $30 \mathrm{~min}$. in each site on a platform $0,064 \mathrm{~m}$ above the ground at $12,00 \mathrm{~h}$, once very week during the dry season (Oct.-Jan.). The exposed plates at the end of sampling were covered and finally incubated at room temperature $25 \pm 4^{\circ} \mathrm{C}$ for three days before observation. Fungal colonies were identified by examining spores and mycelia from them, under microscope. The average number of each fungal colony per Petri dish was calculated. 
Indoor sampling was done in the two hospitals (Central hospital and U.B.T.H. Benin City), in which two sets of three plates were exposed. One set was incubated at $37^{\circ} \mathrm{C}$ for the isolation of thermophilic species while the other set was incubated at room temperature.

\section{Debris sampling}

Debris of different agricultural and industrial materials on which fungi were growing were collected randomly in all the different sampling sites. They were put separately in sterilized, transparent polythene bags, and kept in a humid chamber for 2-3 days in the laboratory to allow for a better development of the fungi. The isolates made from these debris were identified using taxonomic keys.

\section{Use of different food substrates as fungal baits}

For food substrates, namely fresh pieces of yam, boiled meat, butter and onions were exposed outdoors for 2 weeks for fungal attack. This was aimed at finding out the best substrate for trapping Aspergillus sp. in the air. At the and of exposure, the resultant Aspergillus sp. on them were isolated end identified.

\section{RESULTS AND DISCUSSION}

Eleven species of Aspergillus were isolated from the different sites of sampling (Table 1).

The highest record of Aspergillus sp. was in January, with a gradual species fall out to March. Also some species increased their individual concentration from January to March (Fig. 1). This appears to depend on the presence or gradual disapperance of substrate on which the fungus was most commonly found. Yam which is a carbohydrate substrate, recorded the highest number of Aspergillus species (Table 1). Carbohydrates generally constitute the largest and the most available food in Nigeria. However its availability is highest especially at the end of harvest seasons between September and December (for tubers). June-August (for grains). The different carbohydrate wastes during these peak periods easily serve as sources of fungal spores. Other classes of food like vitamins, protein and fat do not easily constitute wastes and hence rarely serve as sources of fungal spores.

Quantitative and qualitative concentration of Aspergillus species varied from one location to another. New Benin Market had the highest record of Aspergillus. It also recorded the highest species concentration. This was related to the different types of wastes in and around the market. These wastes resulting from the lively 
human activities, serve as rich sources of fungal development. Thus, the high concentration of Aspergillus sp, in the air of the New Benin Market correlates with the abundant fungal substrates (wastes) on the market floor. Also human activities like brisk movement and talking in the market help to boots spore liberation and dispersal (G r e g o r y, 1978).

This agrees with the suggestion of $\mathrm{K} \mathrm{z}$ y s of $\mathrm{i} k$ (1978), that air spores can be used as a sanitation index of an environment. Regular and prompt removal of debris can help to reduce the spore load of the surrounding atmosphere. The relatively high standard of sanitation in both hospital premises may have accounted for the low species concentration, since the environment is regularly cleaned, with feur extramural human activities.
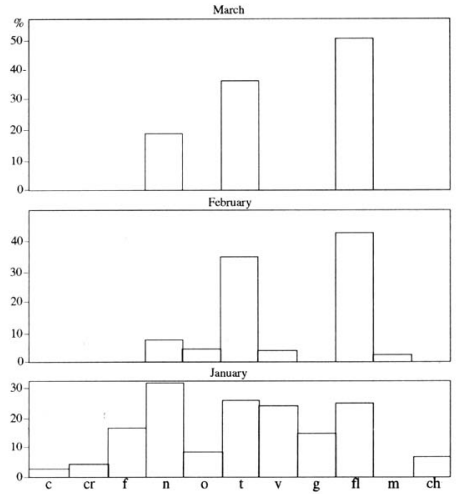

Fig. 1. Mean monthly colony counds (\%) of spores of Aspergillus sp. c-A. candidus, or -A. carboneri, $f-A$. funigans, $n-A$. niger, $0-A$ ochraceus, $t-A$. tamarii, $v-A$ versicolor, $g-A$. giganeous, $\mathrm{f}-\mathrm{A}$. flavis, $\mathrm{m}-\mathrm{A}$. molleus, ch $-A$. chevafieri 
Table 1

Aspergillus species isolated from differeat foct substrates and locations

\begin{tabular}{|c|c|c|c|c|c|c|c|c|}
\hline \multirow[b]{2}{*}{ Species } & \multicolumn{4}{|c|}{ Foot substrates used as traps. } & \multicolumn{4}{|c|}{ Location } \\
\hline & Yam & Meat & Butier & Onions & $\begin{array}{c}\text { New Benin } \\
\text { Marke }\end{array}$ & U.B.T.H. & B.C.H. & Campus \\
\hline A. flavas & + & + & + & . & , & + & + & + \\
\hline A. niger & + & - & - & - & + & + & + & + \\
\hline A. ocharacets & + & , & - & - & + & - & - & + \\
\hline A. tamarï & + & - & + & + & + & - & + & + \\
\hline A. versicolor & + & - & - & - & + & - & - & + \\
\hline A. chevalieri & + & - & - & - & + & + & + & - \\
\hline A. candidus & + & - & - & - & + & + & + & - \\
\hline A. giganteus & + & - & - & - & + & - & - & + \\
\hline A. meilens & + & & , & & + & - & - & - \\
\hline A. fumigatus & + & - & - & & + & - & - & + \\
\hline A. cartonarius & + & - & - & - & - & - & - & - \\
\hline Total & 11 & 3 & 3 & 2 & 10 & 4 & 5 & 7 \\
\hline
\end{tabular}

Acknowledgucut

We are grateful to the technical staff of the Botany Department of the University of Benin, for their assistance.

\section{REFERENCES}

A y a n ru D, K, G, 1981. A gricultural and clinical significance of some nicrobial componenis of the air spore in the Benin City area. Global Inpact of Applied Microbiology. Sixth InL. Conf. p. 107-117 Lagos, Nigeria.

Ca m ma ck R.H., 1955. Seasonal changes in the three common conslitueats of the air spore of Scuthern Nigeria. Nature 176: 1270-1272.

Di a nsfield M. 1966. The fungal air spore at Saruan, Northen Nigeria. Trans. Brit Mycol. Soc. 49:121-132.

Gi e g o r y P. H, 1978. Microbiology of the atmosphere. 2nd edition, Leonard Hill.

Ha rve y R., 1970. Air spore studies at Cardiff. Trans. Brit. Mycol. Soc. 54: 251-254.

Harvey R., 1973. Aerobiological surveys and spore discharge studies of Cardiff, 1942-72. [In]: Scan-

dinavian Aerobiology (Editor S. Nelson). Bult. Ecol. Res. Comm / NFR No, 18, Stockholm.

Harvey R., Mulli as J., 1975. The incidence of aeroallergens in South Wales, Nova Hed wigia 26: 445-460. Hodgkis s I. J., Harvey R., 1970. Effect of humidity and raiafall on spore discharge thythms in pyrenornycetes, Trans. Brit. Mycol Soc. 56: 225-234.

Hu n d s on H. J., 1969. Aspergilli in the air spora at Cambridge. Trans. Brit. Mycol. Soc. 52: 153-159.

Krzy sofik B., 1978. Air micoflors as a hygienic and sanitary index of the health service. [ln]: Proc. 1st Int. Conf. on Acrobiology p 13-15. Eric Schmidı Verlage Betlin.

Mered it h D. S. 1962 . Some components of the air spora in Jamaican basana plantatious. Ann. Appl. Biol.

50: 577.594

Pa d y S M. 1957. Quantitative study of fungus spores in the air. Mycologia 49:339-353.

Ogunlan a E O., 1957. Fungal air spora at Ibadan, Nigeria. App. Microbiol. 29: 458-463.

Shaf uc A, Rahmani T., 1978. Atrospheric mould spores in Teheran. Iran. Ann. Allergy 40, 138-142. 
S r c era mu u u T., S a sh a va ta ra m V. 1962 . Spore content of air over paddy fields. L. Changes in a field near Pentapedu, from 21 September to 31 Decenber 1957, Indian Phytopath. 15:61-74.

Sreer amulu T. Ramaling a m A. 1966. A two year study of the air spora of a paddy field near Visakhapatnam Indian I. Agric. Sci. 36: 11-32. 